\title{
The experience of teacher's academic mobility of the University of Girona (Spain) and I.K. Akhunbaev Kyrgyz State Medical Academy (Kyrgyzstan) in the framework of the international program Erasmus+
} Aliya Kadyrova, Begaiym Kulbaeva

\author{
Radiology Department, I.K. Akhunbaev Kyrgyz State Medical Academy, Bishkek, Kyrgyzstan \\ Key words: education, international collaboration
}

Erasmus+ is a program of the European Union in the field of education, the main purpose of which is to improve the quality of education and the development of mobility. At the same time, cultural exchange takes place among all participants between students and teachers and friendly relations arise. The program also creates the basis for international cooperation for university teachers in various countries.

Department of Radiology of I.K. Akhunbaev Kyrgyz State Medical Academy (KSMA) had the opportunity to establish first relations abroad. From December 10 to December 17, 2018, a series of lectures were given at Universitat de Girona on the course "Biomedical Engineering" at the Superior Polytechnical School in the duration of 10 academic hours. Including duration of four academic hours were given lecture and practice class for students of Facultat de Medicina of same university on the theme of "Pulmonary tuberculosis".

Universitat de Girona is the state system of higher education in Catalonia. The education system is transformed in accordance with the pan-European model (bachelor - master - doctor). MAIA scholarship holders are citizens of countries from all over the world (Morocco, France, Italy, Poland, Costa Rica, Colombia, Bangladesh, Russia, Ukraine, Uzbekistan, Pakistan, Kazakhstan and Kyrgyzstan).

This provided not only educational experience, but also the practice of improving communication skills. In addition, while in Girona, in a cozy city among a mountainous landscape with a rich historical and cultural heritage, students cannot resist knowing new customs and traditions. All this is a huge contribution to the comprehensive development of students.

The lecture participants were students of the third semester of the MAIA of Superior Polytechnical School, master level, in the Diagnostic Visualization and application section. The main goal for the staff of the department was to illuminate the fundamentals of ultrasound and X-ray imaging, where the main focus was aimed at the physical and technical bases: the device of the ultrasound scanner and X-ray apparatus, the principles of their work, image acquisition and imaging, the rules for using technology. However, since it is important for students of a polytechnic school to know "their enemy" that is may arise like some problems during operation of devices including medical imaging, some lectures were given separately on this topic in addition to the themes listed above.

A classification of the functional disturbances occurring during exploitation of medical devices was considered and consolidated the possible ways of their elimination. As an addition, not specified by the parties, small practical classes were conducted with students. Future technicians and engineers could briefly feel themselves like doctors, examining ultrasound and X-ray images of various organs and parts of body and applying the data obtained in practice. The interactive component made a great impression on both sides.

Thirst for knowledge cannot go unnoticed - the students actively asked questions, while the teachers, responding to them, watched the lively discussions between the questioners. Seeing such a desire, it was impossible not to be surprised: the process of giving lectures, which is customary for teachers, became unexpectedly memorable and fun.

It should be noted the search to intellectual exchange of coordinators of the project by Full Professor Xavier Llado, Dr. Arnau Oliver and Dr. Robert Marti. They demonstrated a brief presentation of the research and professional activities of Superior Polytechnical School. Practicing doctors, of course, were interested in the development of Spanish colleagues at the border of diagnostics and oncology: the working group had designed a device that would quickly and efficiently examine individuals for skin cancer and precancerous conditions. Patients are placed in a chamber where skin elements are fixed at high speed using high-resolution cameras. Data storage allows you to assess the status of patients over time. This opportunity has a significant potential contribution to the diagnosis of skin diseases growing every year.

Address for Correspondence: Aliya Kadyrova, Radiology Department, I.K. Akhunbaev Kyrgyz State Medical Academy, Bishkek, Kyrgyzstan; Email: al-kadyrova@yandex.ru

Received: 03.02.2019 Accepted: 04.02.2019

Copyright 2019 Heart, Vessels and Transplantation Doi: 10.24969/hvt.2019.105 
Another memorable event is a visit a seminar of Module "Medical Robotics" in the Hospital Josep Trueta, the use of the Da Vinci Robot. After the theoretical part about the possibilities and advantages of the robotic system, the coordinators of the seminar, in particular Dr. Xavier Cufi, in practice demonstrated the operation of the system. The advantages of this system are obvious: the operating endovideo surgeon no needs to be in poorly comfortable conditions with a shaking camera; he can be located behind a separate unit. Observation of the surgical field takes place through a separate stable access, while two pairs of manipulators are located on the sides. Now, not only the students of the Polytechnic University, but also the practitioners of the radiology department were able to feel themselves as surgeons for a short moment.

Long-awaited lectures on pulmonary tuberculosis for students of Facultat de Medicina took place closer to the end of the trip. However, before that, there were meetings with Dr. Salvador Pedraza (Head of the Radiology Hospital of Josep Trueta) and Teresa Puig (Teacher UdG Medicina and researcher (Targets Lab / Oncology)). The traditional introduction to phthisiology had gone to a lively discussion of the relevance of tuberculosis. It is no secret that lately in the countries of the European Union there is a huge stream of immigrants that possibly changes of the epidemiological situation. Kyrgyz doctors have experience in diagnosing tuberculosis, as the problem remains relevant at the moment. The main part of the lectures was presented in the form of six clinical cases of pulmonary tuberculosis. And despite the fact that the students were not only medical students, which the lecturers hoped for, but there were also medical biologists, chemists, nurses and the material was received with interest. And after that again a practical mini-part which had already become traditional in our practice. This time the teachers showed 28 radiographs, which went all the way from Kyrgyzstan to Spain.

In summary, we would like to express our gratitude for participating in the Erasmus+ program. It allowed us to get enormous experience in creative development. Because being far from the details of the technical side of medical imaging, the lecturers faced a difficult task - to bring the training course to the students of the polytechnic school. And the main goal in view of generating the interest of students had been achieved. Analyzing technical aspects, in turn, they were able to visually see the "fruits" of their future activities. In the medical field, it is always saving lives and improving quality. Such involvement forces us to consider learning not only as a process but also as the persecution of a noble goal to be useful to society. And together with a multinational group the goal to develop interaction skills.

Returning home, of course, many plans for the future have appeared: the development of international relations and research activities, and most importantly desire to continuous self-education. And this is a key to development and prosperity. 


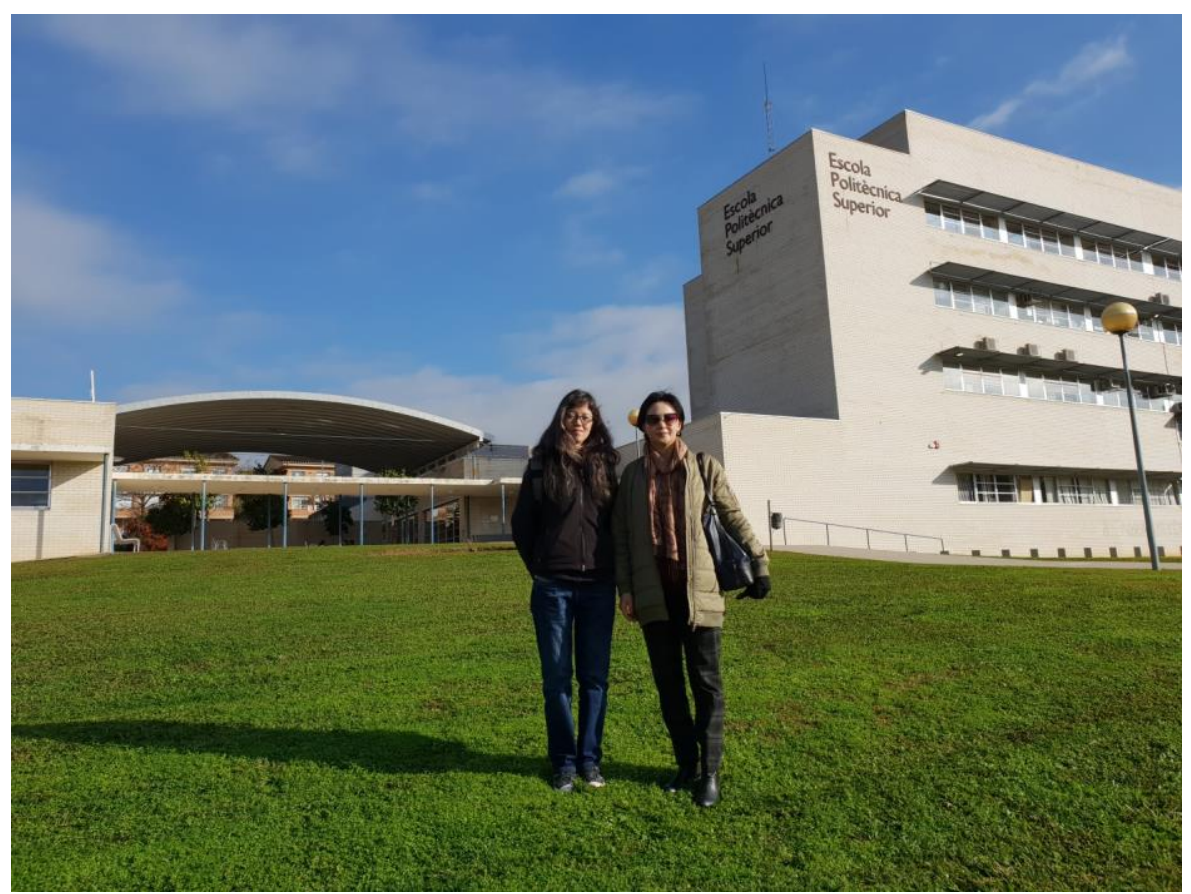

Figure 1. Aliya Kadyrova and Begaiym Kulbaeva - in the front yard of the main building of Higher Polytechnic School

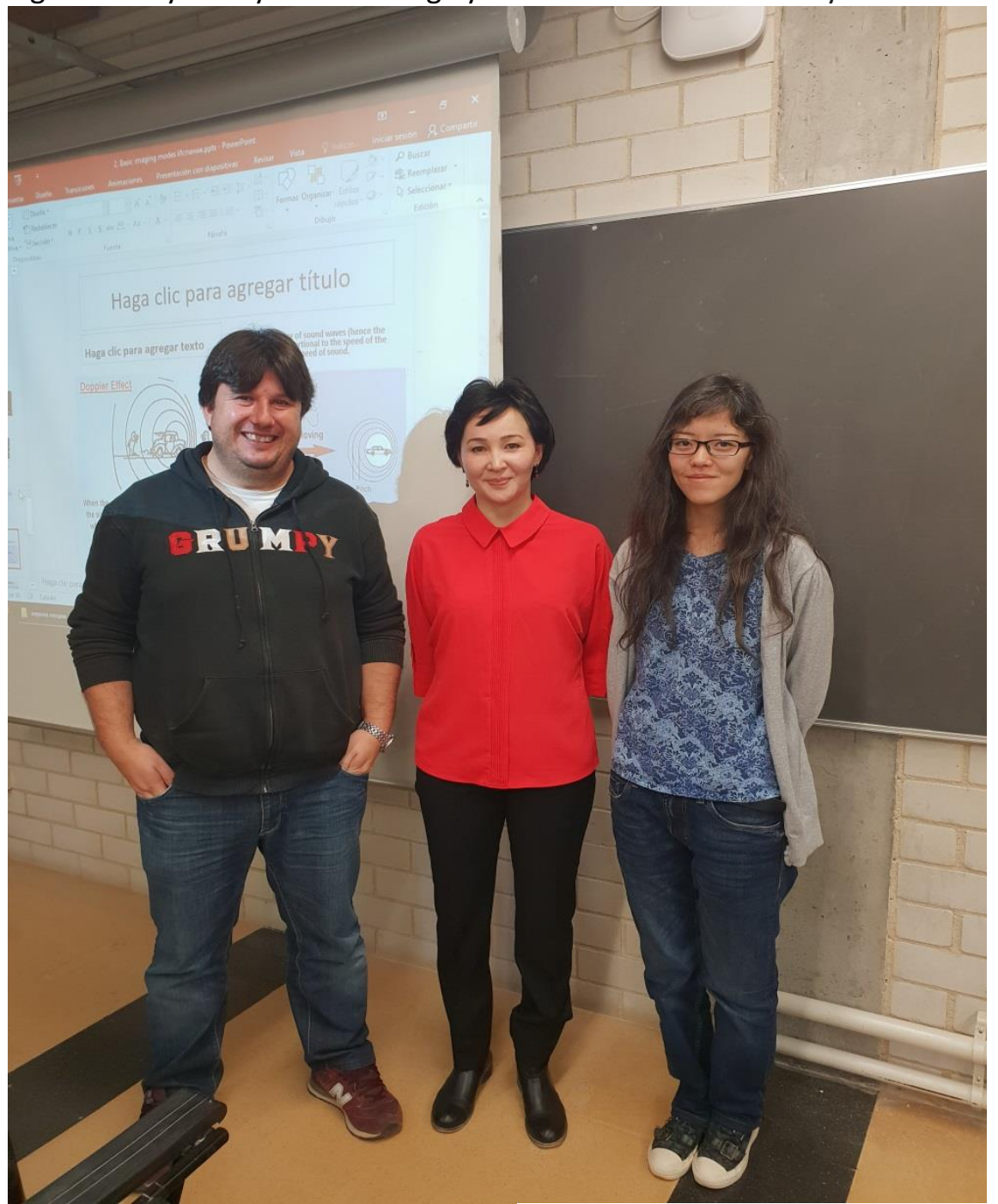

Figure 2. In a break between lectures. Arnau Oliver, Aliya Kadyrova and Begaiym Kulbaeva 


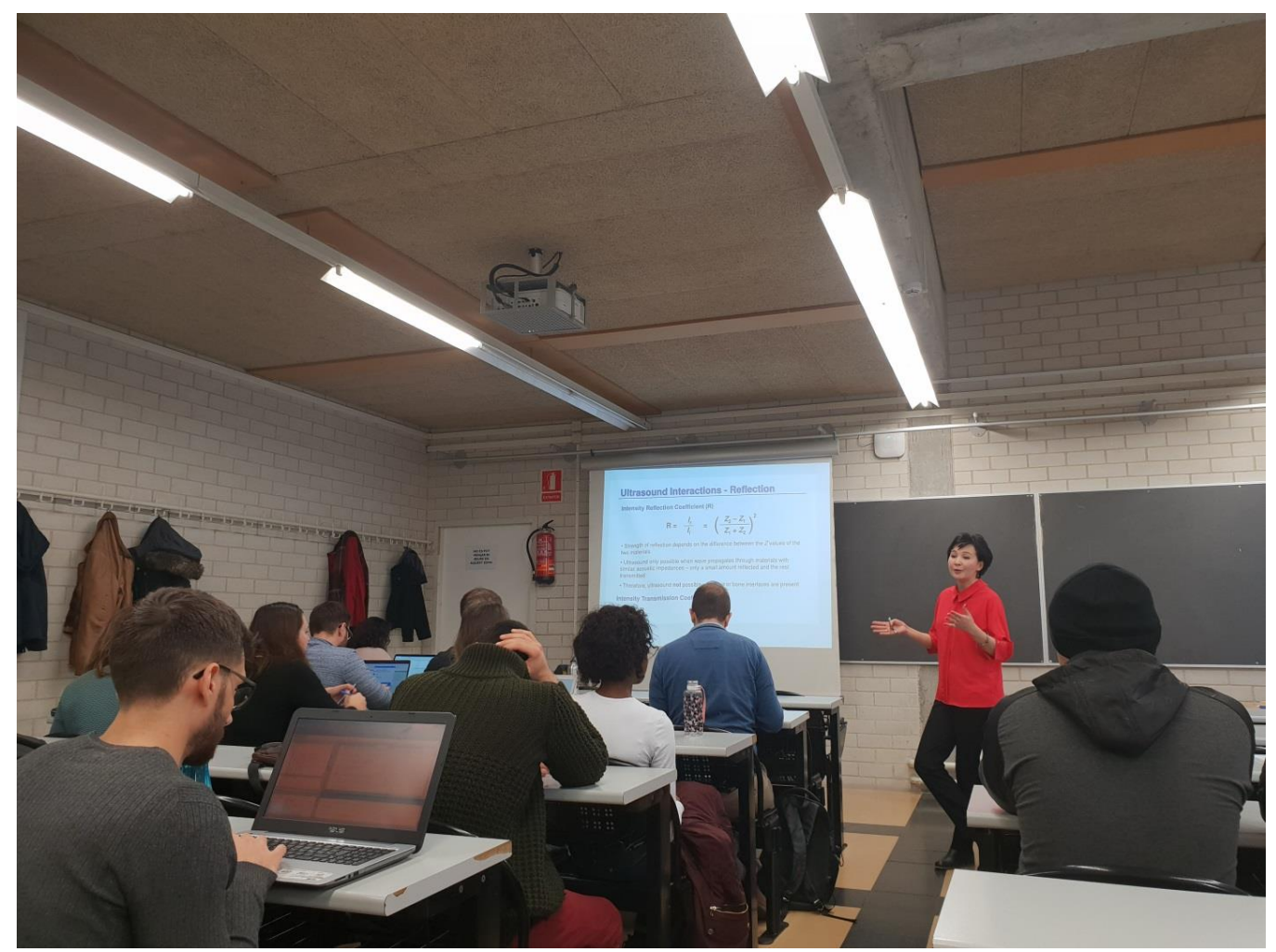

Figure 3. Lecture in a progress, lecturer Aliya Kadyrova.

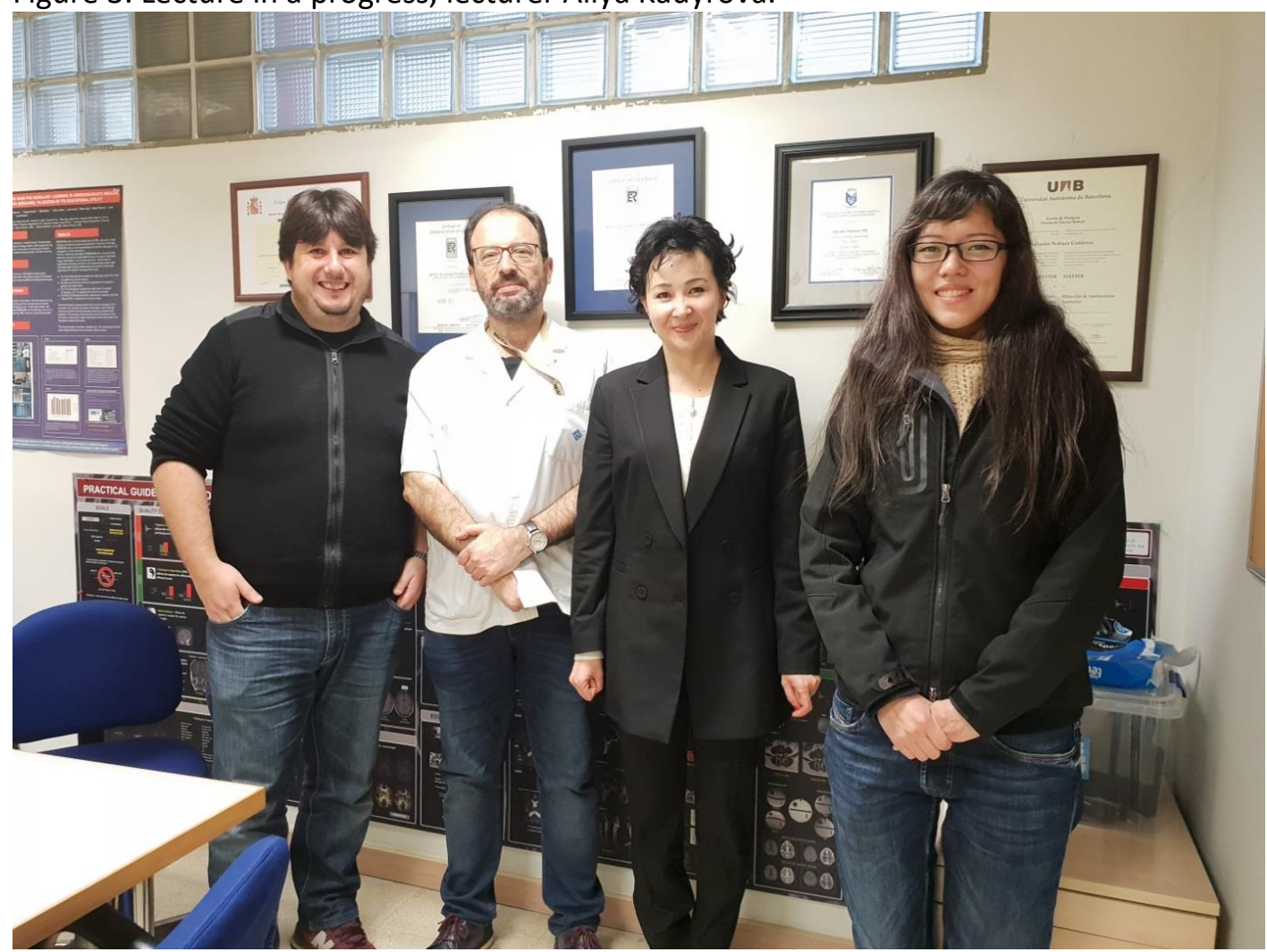

Figure 4. Meeting and acquaintance with Dr. Salvador Pedraza (Head of the Radiology Department of Hospital Josep Trueta). Left-to-right: Arnau Oliver, Salvador Pedraza, A. Kadyrova and B. Kulbaeva 


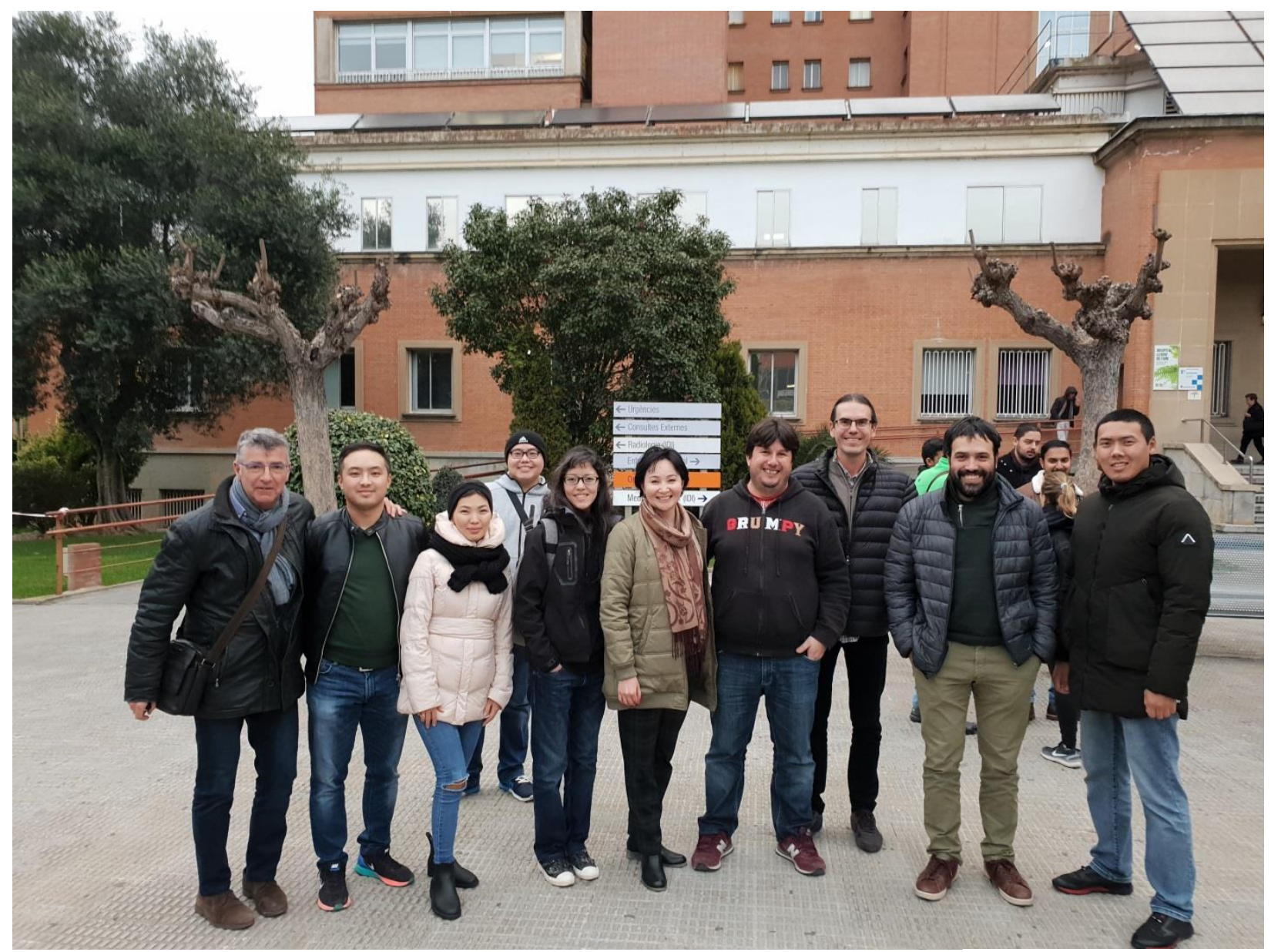

Figure 5. Memorial photo before the seminar "Medical Robotics" in the yard of Hospital Josep Trueta, Girona. University professors of Superior Polytechnical School and students of Erasmus+ program (residents of I.K. Akhunbaev KSMA). Xavier Cufi, K.Pan, Turatbek Ch., Yrysov B., Kolbaeva B., Kadyrova A., Arnau Oliver, Xavier Llado, Robert Marti and Melisov B 


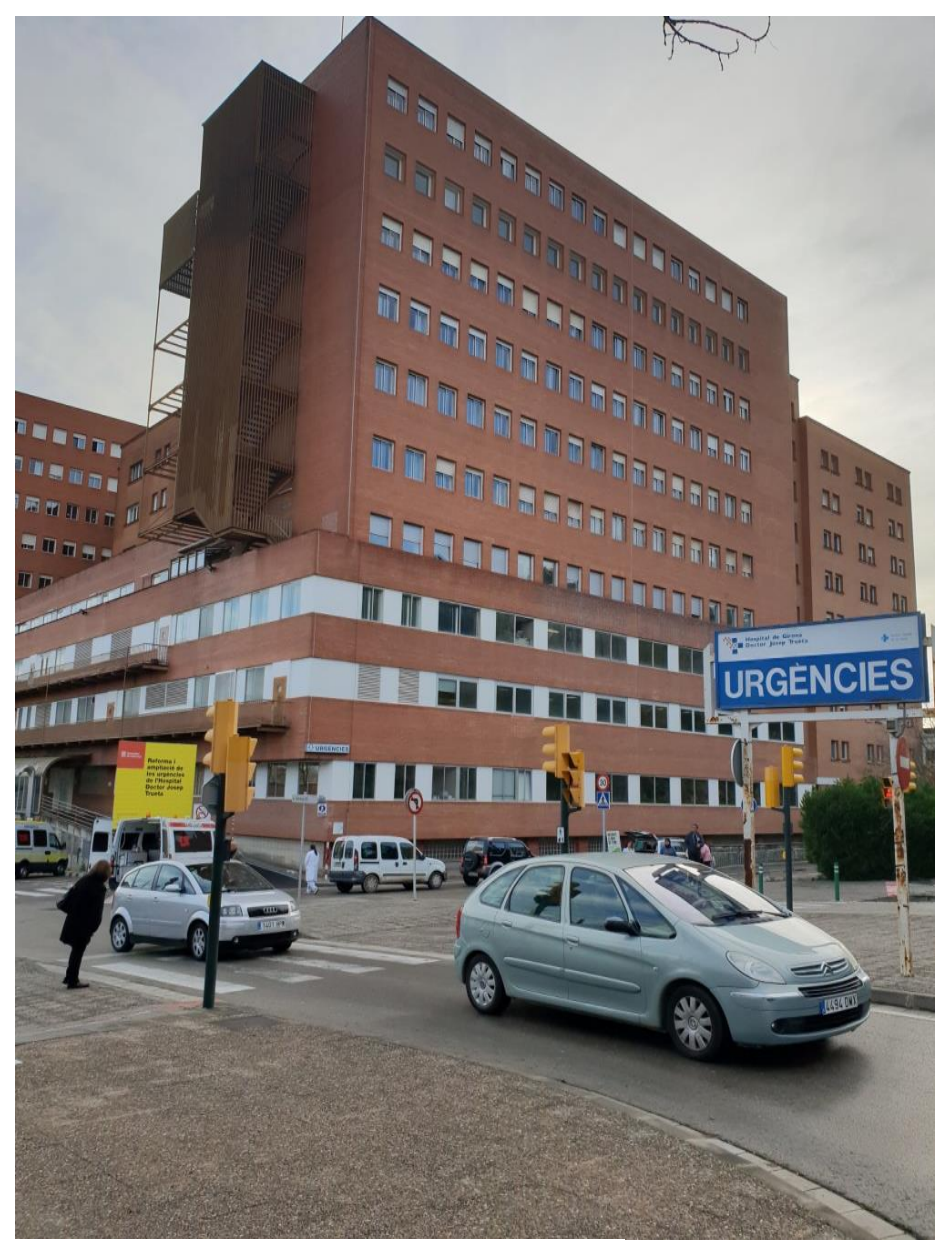

Figure 6. Hospital Josep Trueta, Girona.

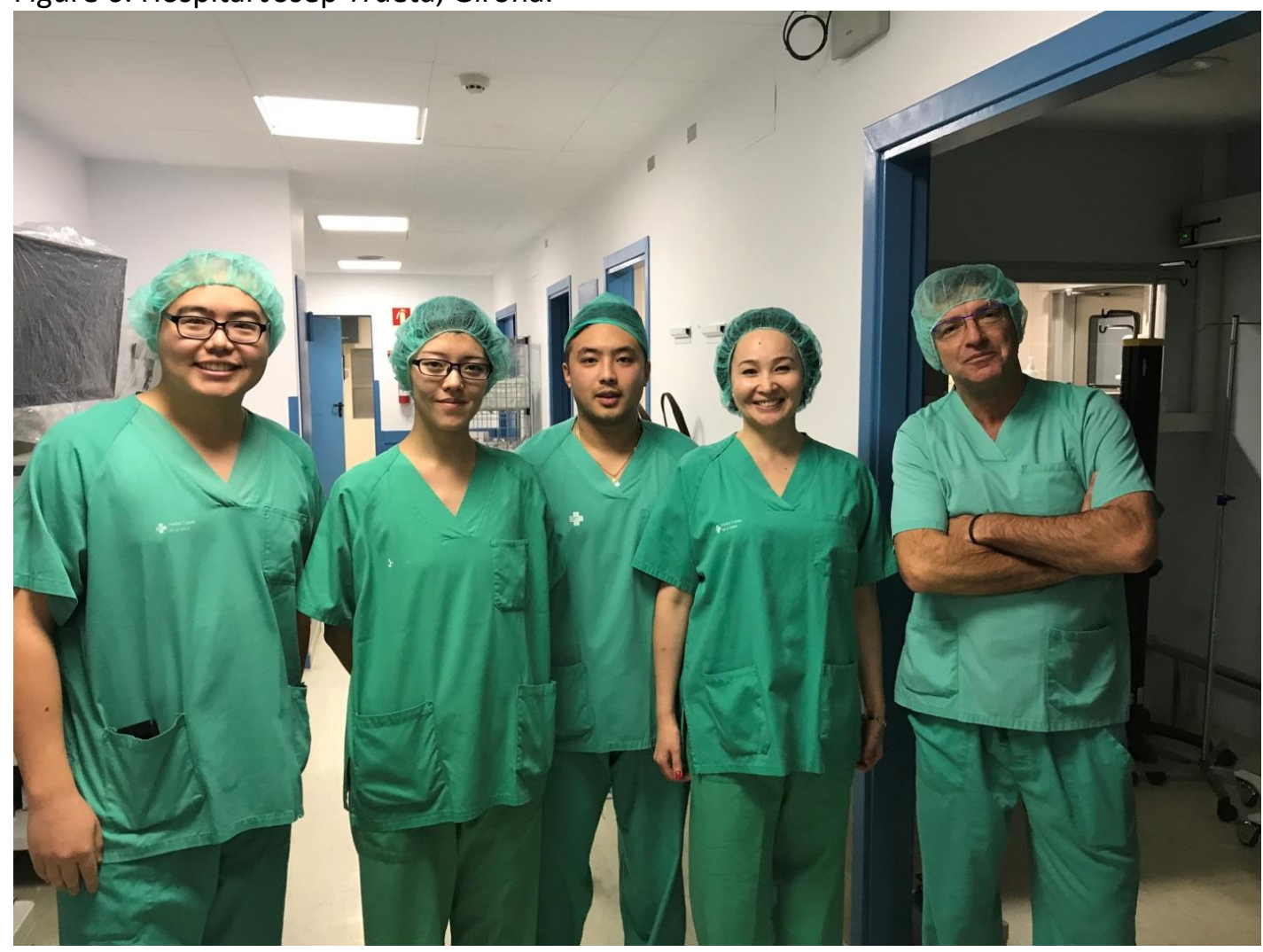

Figure 7. During the practical training of Robotic technology. Presentation of Da Vinci Robot. On the photo Kyrgyz teachers and residents of KSMA (Yrysov B., Kolbaeva B., Pan K., Kadyrova A.) and Xavier Cufi (University of Girona) 


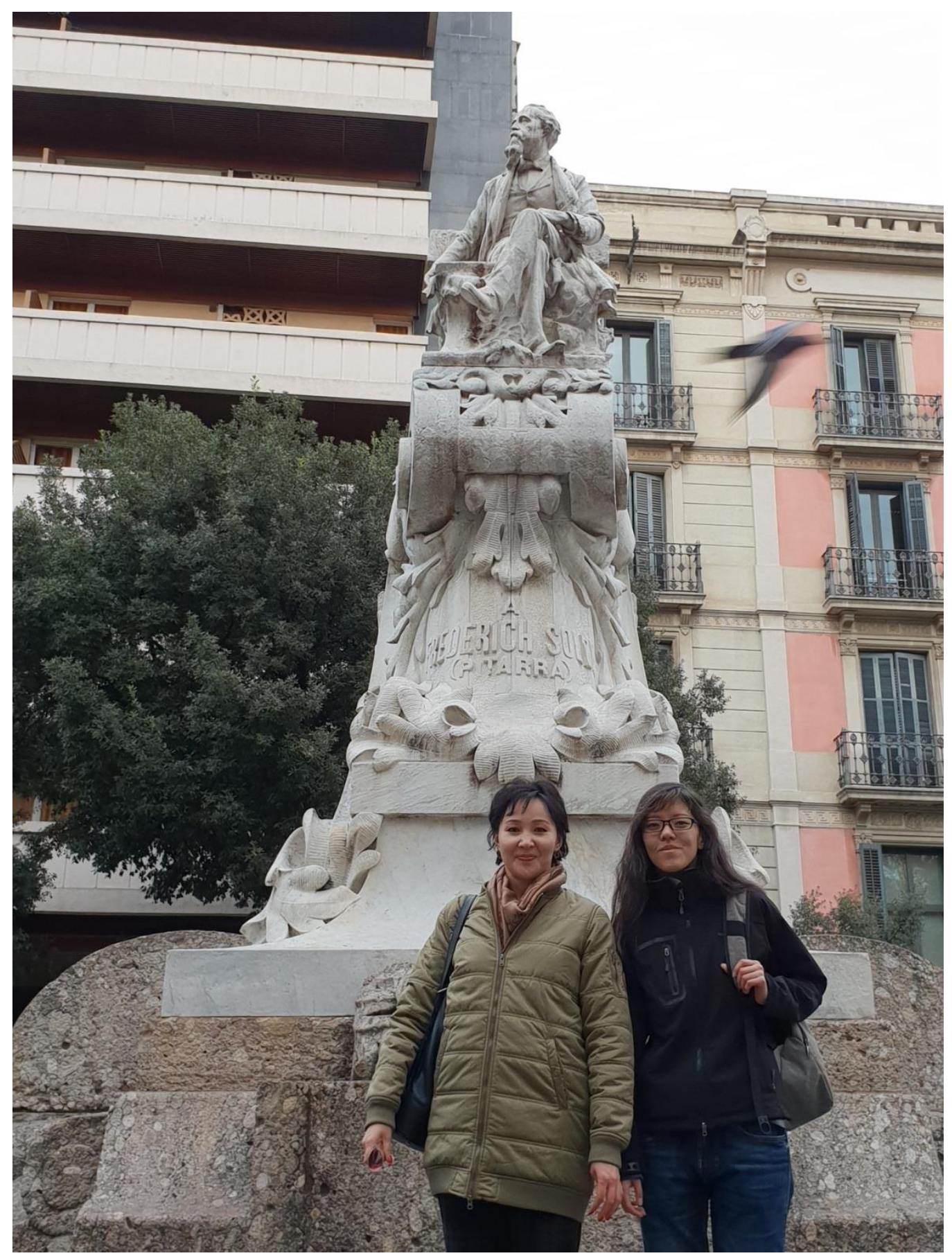

Figure 8. On leisure time, sightseeing in Barcelona 